\title{
BEIJING 2008: OS JOGOS OLÍMPICOS, A CIDADE E OS ESPAÇOS'
}

\author{
DR. OTÁVIO TAVARES \\ Doutor em Educação Física pela Universidade Gama Filho \\ Professor Associado do Centro de Educação Física e Desportos da \\ Universidade Federal do Espírito Santo (UFES) \\ Docente do Programa de Pós-Graduação em Educação Física da Universidade \\ Federal do Espírito Santo (UFES) (Vitória - Espírito Santo - Brasil) \\ e-mail: otaviotavares@pq.cnpq.br
}

\begin{abstract}
RESUMO
Este artigo tem como objetivo analisar a organização e o relacionamento dos espaços de Beijing e dos Jogos Olímpicos de 2008. Foi adotado como referência o conceito de "palco de operação' de Giddens, princípios da microssociologia de Goffman e as categorias da sociologia do espaço de Simmel. Pude observar como os espaços 'olímpicos' tornam-se exclusivos. Suas fronteiras os tornam divididos e delimitados. São fixados para uma determinada expectativa de atuação e para criar uma dimensão sensorial de identidade e temporalidade próprias. Por outro lado, encontramos limites para pensar na fluidez dos espaços. Em conclusão, os Jogos adquirem atributos espaciais que transcendem a identidade da cidade e seu caráter de interação parece estar relacionado ao projeto político do país sede.
\end{abstract}

PALAVRAS-CHAVE: Jogos Olímpicos; espaços; Beijing; cidade.

I. O presente estudo teve apoio financeiro da CAPES aux no. I 406-08-6. 
"A China inquieta-me"

Blaise Pascal $^{2}$

\section{INTRODUÇÃO}

Imagine-se chegando, após mais de trinta horas de deslocamento, ao outro lado do mundo. Mais precisamente a Beijing, capital da China. Atual República Popular, antigo império milenar. As instalações do aeroporto, como de resto quase toda a infraestrutura de transporte de massa em Beijing, são bastante novas, tendo sido grandemente ampliadas e modernizadas para os Jogos. Há uma excitação no ar. Um movimento intenso de passageiros chegando, muitos uniformizados com roupas coloridas, como cartazes ambulantes informando o país de procedência e/ ou as empresas as quais estão ligados, e centenas de funcionários chineses dispostos a sorrir e dar informações. Ao contrário do que poderia esperar, os trâmites da imigração são rápidos, o oficial simpático e o mais surpreendente: um pequeno painel eletrônico pede que eu avalie a qualidade de seu atendimento.

O inglês, língua franca, entre outras coisas, do turismo internacional, é a ponte de contato possível, pois o idioma local é, para mim, impenetrável. A escrita e a fonética são claramente incompreensíveis para a grande maioria dos viajantes que chegam àquele lugar. Como seria lembrado mais tarde, a incompreensão é, geralmente, uma via de mão dupla, de modo que a quantidade de chineses, mesmo trabalhando em atendimento ao público, que conseguiam comunicar-se em inglês era muito baixa. Salvou-me o guia impresso bilíngue. Num país de gestos contidos e tradição de vigilância mútua, a mímica não conseguia comunicar nem mesmo coisas simples.

Desde Marco Pólo a China é vista como um lugar desconhecido. O mais oriental dos orientais, cujas narrativas idealizadas ilustram aquilo que Edward Said (2007, p. 27) chamou de orientalismo, "um modo de abordar o Oriente que tem como fundamento o lugar especial do Oriente na experiência Ocidental europeia" e sua condição de invenção pelo ocidente. Como tal, o orientalismo ajudou a definir simultaneamente as compreensões do ocidente sobre si mesmo e do oriente como seu "outro". Neste contexto, são antigas as narrativas sobre a letargia do homem

2. Citado por Jullien (1996, p. 164). 
chinês, a ausência de um espírito agonístico e o caráter intelectualizado e efeminado de sua civilização, em oposição ao energético e competitivo ocidente, cristalizadas na imagem do "homem doente da Ásia" (BROWNELL, 2008).

Nova potência emergente, a China, é mais uma vez um claro enigma que evoca imagens contraditórias. Tradição e modernidade, capitalismo e dirigismo estatal, tecnologia e produtos baratos, riqueza e pobreza. Sua mais recente ação para estabelecer-se como potência no cenário internacional é sediar a XXIX edição dos Jogos Olímpicos da era moderna. Megaevento contemporâneo de tradição secular e alcance planetário, os Jogos Olímpicos serão para os chineses, o que já foram para japoneses em 1964, coreanos em 1988 e espanhóis em 1992: uma festa de reconhecimento de seu novo status internacional (CLOSE; ASKEW; XIN, 2007) e uma maneira de apagar definitivamente a imagem do "homem doente".

Estou chegando a Beijing para participar de um simpósio internacional sobre estudos olímpicos ${ }^{3}$ que acontece imediatamente antes dos Jogos e ficarei por dez dias na cidade. No trânsito entre o aeroporto e o hotel, pude confirmar imediatamente que o ar cinza que toma a cidade impede que se enxergue claramente não mais que nesgas do azul do céu e prédios imensos a cerca de uns dois a três quilômetros. $\bigcirc$ clima é seco, quente e abafado. Beijing é uma cidade de quase quinze milhões de habitantes, cinco anéis viários, avenidas muito largas, prédios imensos e quarteirões muito grandes que possuem, geralmente, uma entrada guardada, ruas internas e múltiplas ocupações. Na verdade, sua urbanização mais recente vai substituindo gradativamente a antiga, baseada nos hutongs - espécie de quarteirões com residências voltadas para dentro, de cor cinza, sem janelas para fora, pátios internos, banheiros coletivos, um ar ruim e um jeito insuperável de "cabeça de porco". A maioria dos prédios residenciais têm aspecto pouco cuidado, grades em todas as janelas nos três ou quatro primeiros andares, pequenas varandas que parecem ser depósitos residenciais e banheiros coletivos nos andares ${ }^{4}$.

Por outro lado, jardins bem cuidados exibem arranjos ou figuras que evocam os Jogos. Bandeiras com motivos olímpicos decoram milhares de postes em toda a cidade, assim como é praticamente impossível encontrar um cartaz qualquer, grande ou pequeno, que não exiba a propaganda de um patrocinador olímpico. Os Jogos estão em toda a parte. Os tapumes que cercam as obras na cidade, todas paralisadas

3. 9th International Symposium on Olympic Research. Evento organizado pelo International Centre for Olympic Studies (University of Western Ontario - Canadá) e Capital University of Physical Education (Beijing - China).

4. Tudo isto e a existência de um bairro nobre como Chaoyang e as salas VIP's em agências bancárias me chamou particularmente à atenção, dando materialidade a progressiva eliminação de minhas mitologias sobre a China como um país socialista. 
como forma de amenizar os problemas da cidade ${ }^{5}$, exibem com alegre fundo colorido, em diversos idiomas, o lema: "Um mundo, um sonho"6. Ao chegar ao hotel, bastante próximo de instalações de treinamento e das residências de centenas de voluntários, comecei a ter uma sensação de deja vú. Todas aquelas bandeiras, os símbolos, os uniformes em azul e bege dos voluntários, as formas e cores da sinalização. Tudo aquilo me pareceu imediatamente familiar, lembrando o que já havia presenciado nos Jogos de Sydney (2000), Atenas (2004) e no Pan do Rio (2007). De fato, não ignorava que a existência de todo um sistema organizado de transferência de conhecimento entre organizadores de megaeventos esportivos ${ }^{7}$ poderia produzir uma organização semelhante, apenas ainda não havia notado isto tão claramente.

Isto me pareceu ser um indício significativo na medida em que Beijing reafirmava com seu lema, "Um mundo, um sonho", um discurso de pretensões globalizantes, ao mesmo tempo em que buscava fazer dos Jogos um marco específico de identidade e posicionamento. É preciso observar que tal pretensão realiza-se nos marcos de um evento que é entendido como uma celebração e uma ritualização dos valores da modernidade ocidental, ainda que sujeitos a mediações culturais (ARCHETTI, 1995; DaMATTA, 2003; LOLAND, 1995; MacALOON, 1987). Neste contexto, ainda que Durkheim nos tenha ensinado que quanto mais plurais tornam-se os grupos sociais, mais abstratas necessitam ser suas representações coletivas, a realização do evento olímpico em países como Japão, Coréia e China podem tornar-se "laboratórios" para o estudo de fenômenos de aculturação. Por outro lado, se acompanharmos DaCosta (2002), podemos entender os Jogos Olímpicos como um ritual secular com múltiplos níveis de significado, podemos igualmente questionar em que níveis e como se ajustam as demandas entre o local e o global ${ }^{8}$.

É claro que tal questão poderia ser desdobrada em um conjunto de questões mais específicas abordadas de diferentes formas ${ }^{9}$. Em face da oportunidade, me propus

5. O deslocamento de indústrias, a retirada das ruas de parte da frota de veículos, adoção do gás como combustível dos ônibus, a suspensão do racionamento de água foram algumas das outras medidas adotadas pelos governos locais.

6. Lema este bastante semelhante ao dos Jogos Olímpicos de Inverno em 1998 em Nagano, Japão: "Um mundo, um coração".

7. Este sistema é uma preocupação do Comitê Olímpico Internacional para com a qualidade dos Jogos materializada em uma empresa (Event Knowledge System) e um sistema (Olympic Games Knowledge Management Extranet) com este fim específico, e realização de uma série de outros procedimentos obrigatórios de transferência de conhecimentos.

8. Ou entre o oriental e o ocidental, o despotismo e a liberdade, o imóvel (em Chinês: jing) e o ativo (em Chinês: dong).

9. Poderíamos investigar, por exemplo, como se configuram as políticas de identidade chinesas em função de seus projetos de inserção internacional. Ou testar as teses de antropólogos como Eduardo 
a fazê-lo em sentido radicalmente diverso daquilo que se poderia esperar diante de um objeto definido como "mega". Sem uma estrutura de pesquisa previamente planejada, coloquei-me na condição definida por Goffman como uma "unidade de deslocamento em movimento" (GOFFMAN, 1963 apud JOSEPH, 2000). Como o pesquisador que vagueia observando os fenômenos diretamente a partir de um foco absolutamente loca-

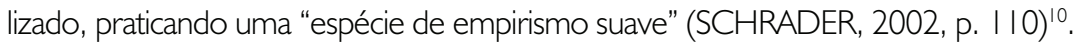

Como estava claro desde o início, a língua, as condições de acesso a determinadas instalações e o tamanho da cidade condicionavam o que poderia ser observado. Assim, necessitava definir um objeto e uma posição estratégica, de onde o observado se tornasse visível numa constelação espacial e temporal típica de modo a evitar uma observação difusa (JACCOUD; MAYER, 2008). Diante de meu estranhamento original, o que me pareceu possível naquele momento era definir como objeto as configurações dos espaços da cidade relacionados à realização dos Jogos. Afinal, a diferenciação espacial significa, como Norbert Elias comprova em diversos exemplos, uma separação das ações sociais. Isto significava, em um sentido mais estrito, observar as instalações esportivas, as arenas de competição, as instalações de rua (telões, palcos e espaços para performances) e em um sentido amplo, a própria ambientação da cidade " como palcos de operação, ou seja, como lugares cuja organização espacial guarda relações significativas com a organização social.

Numa perspectiva microssociológica, o que transforma uma área física em uma entidade sociologicamente pertinente são as regras que permitem controlar a ordem dos lugares e a comunicação entre os participantes, ou seja, a estrutura normativa dos territórios espaciais ou temporais. Assim, achei possível analisar como a estrutura normativa dos territórios "olímpicos" de Beijing materializava a articulação entre o projeto chinês de identidade no âmbito local e o discurso universalista dos Jogos e como tais vetores contrapostos se afetavam mutuamente. Para a realização deste objetivo lancei mão dos atributos do espaço propostos por Georg Simmel em sua sociologia do espaço (SIMMEL, 1983; SCHRADER, 2002), como forma de dar um tratamento sistemático as observações realizadas. Para ele, os espaços:

Archetti e John Macaloon que afirmam serem os Jogos um ritual de celebração da modernidade ocidental e do indivíduo, em face da cerimônia de abertura dos Jogos de 2008 e dos discursos orientalistas sobre a China.

I0. Segundo Schrader (2002, p. I I0), "Se a alteração do espaço de sondagem for válida como procedimento social em determinada situação, o pesquisador social pedestre pode melhor reunir informações deliberadamente e adquirir conhecimentos do que aquele observador imóvel ao qual se refere a literatura metodológica".

II. Metodologicamente falando, estariam eliminadas questões relacionadas as possibilidades de observação séria da cultura local e a necessidade ou não de tornar-me um observador oculto. 
a) são exclusivos, b) podem ser subdivididos e delimitados, c) são fixados para a representação social, d) permitem proximidade sensorial, e) podem ser trocados.

\section{OS JOGOS, A CIDADE E SEUS ESPAÇOS}

\section{OS ESPAÇOS OLÍMPICOS SÃO EXCLUSIVOS}

Uma instalação olímpica é sempre um espaço de destinação exclusiva. Sua organização se dá de tal forma que outros usos e destinações ficam temporariamente excluídas, o que para Simmel é bastante significativo. Nada ali compete e nenhuma outra possibilidade de uso é possível, a não ser que seja acessória da atividade principal'2. Isto parece ser banal quando pensamos nos ginásios e estádios que tipicamente conhecemos, mas ganha significado quando observamos que uma grande quantidade de instalações são construções provisórias e/ou adaptações de outros espaços. Tecnicamente, são chamadas em inglês de overlay, palavra que significa encobrir (To place upon something else), sobrecarregar, revestir e, também, oprimir. As arenas de vôlei de praia são exemplos típicos de overlay. Em Beijing, na ausência de praia, sua instalação no Parque de Chaoyang foi feita de tal forma que não havia em torno dela nada que lembrasse um parque como os diversos existentes na cidade, com sua intensa e multifacetada utilização popular ${ }^{13}$. Sua destinação exclusiva e o empenho para que nada fora do previsto acontecesse são comparáveis ao uso das águas da lagoa Rodrigo de Freitas, no Rio, durante as competições de remo e ski no Pan-americano de 2007, ou da baía de Sydney (2000) nas competições de vela e triatlo, por exemplo. A materialização desta exclusividade não reside apenas nos espaços abertos, também podendo ser evidenciada, por exemplo, no uso do centro de convenções Riocentro no Pan do Rio. Suas imensas instalações projetadas para receberem diversos eventos ao mesmo tempo tornaram-se um espaço único para atividades do Pan-americano, garantindo sua exclusividade.

Esta forma de destinação se estende, de algum modo, a cidade e a regiões vizinhas. De fato, o Comitê Olímpico Internacional "proíbe" que a cidade-sede receba ao mesmo tempo outros megaeventos durante o período de realização dos Jogos tentando dar a ela um destino exclusivo (INTERNATIONAL OLYMPIC COMMITTEE, 2007, p. 76). Do mesmo modo, quando as competições necessitam

12. Como a venda de alimentos e souvenires, por exemplo.

13. Pude observar como os parques da cidade são utilizados por inúmeros grupos que cantam, dançam, praticam ginásticas diversas, fazem arte, lanches ou simplesmente passeiam. 
ser realizadas em regiões próximas, estas ganham também seu caráter exclusivo. $\mathrm{Na}$ China, uma área bastante grande na região da Grande Muralha e das Tumbas Ming, patrimônios culturais da humanidade e destinos turísticos por excelência, ficaram fechados à visitação no dia das provas de ciclismo de estrada, mesmo as provas acontecendo em rodovias diferentes daquelas que davam acesso aos pontos turísticos. É claro que devemos aceitar que este uso está baseado em decisões racionais a respeito do tamanho e das condições de gerenciamento do evento, mas sua consequência é que, neste contexto, as marcas da utilização e as formas de circulação habituais dos espaços desaparecem, transformando-os em algo distinto, em algo que não faz mais parte temporariamente da cidade.

\section{OS ESPAÇOS OLÍMPICOS SÃO DIVIDIDOS E DELIMITADOS}

Segundo Simmel ( 1966 apud SCHRADER, 2000, p. I1 9), "a fronteira não é um fato espacial com consequências sociológicas, mas um fato sociológico que se amolda espacialmente". A busca por exclusividade dos espaços leva a sua divisão e ao estabelecimento de fronteiras artificiais que delimitam os espaços e detêm o cidadão não autorizado, aquele que não tem o "passaporte olímpico" ou o ingresso correto. Diferente das áreas urbanas planejadas cujo isolamento não é perfeito e portanto de alguma forma se integram ao entorno da cidade, as instalações olímpicas possuem delimitações mais rígidas, embora de temporalidade limitada. Tais fronteiras, sempre mais amplas que os locais de competição, são regidas por regras claras que reafirmam, cada vez mais, segurança, exclusividade e diferença. Em Sydney, era possível chegar ao Parque Olímpico ${ }^{14}$ por ônibus ou trem e apenas lá enfrentar os controles de entrada, o que permitia aos indivíduos pelo menos visualizar o complexo. Do mesmo modo, no Rio, em 2007, o isolamento da maioria das instalações não era tão grande a ponto de impedir sua presença visual na cidade, o que matizava suas fronteiras. Em Beijing, as fronteiras do local onde foram construídos o estádio, o parque aquático e a arena do vôlei de praia eram tão distantes que não era possível ao indivíduo que não fosse portador de ingresso ou credencial sequer enxerga-los.

De maneira análoga a um controle de embarque ou de imigração, os procedimentos de entrada numa instalação olímpica envolviam o exame do ingresso, a passagem das pessoas e bolsas por controles de raio x bastante sensíveis e o exame visual dos equipamentos carregados. No verso de cada ingresso era possível ler

14. Local onde estavam localizados o estádio, os ginásios, o parque aquático e as arenas para as competições de tênis, baseball, softball, entre outros. 
doze termos e condições de uso dos tíquetes, proibindo entre outras coisas, o uso de instrumentos musicais, paus de bandeiras ${ }^{15}$, bandeiras de países e regiões não participantes dos Jogos, faixas e cartazes, bandeiras maiores que $2 \times 1$ metros. Também não era possível entrar com nenhum tipo de comida ou bebida, fazendo das latas de lixo imensos depósitos de garrafas d'água e pacotes de doces e salgados. Assim se reduziam os riscos, mas também as singularidades.

Por outro lado, pude perceber como os usos e as delimitações no espaço das cidades podem variar. Olhados em um mapa da cidade, as instalações olímpicas, com suas fronteiras definidas, circulação limitada e uso exclusivo são quase que enclaves no ambiente urbano, porém, os usos e as delimitações da própria cidade em relação aos Jogos são distintas na maneira como alteram seus tempos, espaços e até mesmo suas práticas. Devido a força do regime, em Beijing foi possível paralisar todas as obras, suspender o racionamento de água e proibir uma parte da frota de carros de circular ${ }^{16}$. Do mesmo modo, os hotéis destinados a "família olímpica"17 tinham seu quarteirão inteiramente isolado. A isto se some a existência de ruas fechadas, vias exclusivas e linhas expressas criadas e podemos imaginar o quanto a circulação na cidade se altera e seus impactos no cotidiano dos seus cidadãos. Tais fronteiras garantem a unidade dos espaços olímpicos, o que no plano urbano atingiu níveis ainda maiores de delimitação do que em eventos anteriores. Assim, é possível pensar como as instalações olímpicas se configuram em espaços claramente diferenciados no seio da cidade e se questionar o quanto dialogam com seus cidadãos e visitantes autônomos.

\section{OS ESPAÇOS OLÍMPICOS SÃO FIXADOS PARA UMA EXPECTATIVA DE ATUAÇÃO}

Todo o espaço está sujeito à regulação social que determina qual uso deles se pode fazer. Mesmo os chamados espaços públicos não podem ser encarados de outra forma. Mesmo assim, podem funcionar como palcos de operação para indivíduos e grupos com motivações muito diversas. Contudo, nas arenas e espaços olímpicos estas operações sofrem muitas restrições, tanto pelo que os frequentadores são autorizados a fazer, mas também pelo que eles são conduzidos a realizar em suas ações recíprocas.

15. Pequenos mastros de plástico eram muitas vezes aceitos.

16. Parte destas informações foi obtida pela leitura da mídia estrangeira, parte foi obtida em conversas com colegas chineses de longa data.

17. i.e. todo o conjunto de dirigentes esportivos internacionais, nacionais, dirigentes de empresas patrocinadoras, autoridades governamentais e convidados ligados de alguma maneira aos Jogos e credenciados para isto. 
Como observado anteriormente, existem restrições, que se fazem crescentes se comparadas às edições anteriores dos Jogos, ao que se pode usar para torcer (instrumentos, bandeiras, faixas). Do mesmo modo, fazia parte dos termos e condições de uso dos tíquetes em Beijing (BEIIING ORGANIZING COMMITTEE OF THE OLYMPIC GAMES, 2008) o alerta que "qualquer comportamento que venha perturbar o tranquilo e ordeiro progresso da seção ou perturbe outros espectadores [...] ou viole as leis e regulamentos chineses" era proibido. Como é óbvio, o caráter genérico desta definição deixa os indivíduos sem saber se, e quanto, suas ações poderiam ser estigmatizadas.

Por outro lado, parece mais importante observar como o comportamento da torcida é, cada vez mais, conduzido oficialmente, resultando num enquadramento moral do esporte e das formas de torcer de maneira mecânica semelhante ao que Toledo (2002) identificou nas primeiras formas uniformizadas de torcer no futebol brasileiro. Pouco se conhece sobre o espectador olímpico, mas é evidente que ele é bastante diferente do torcedor ordinário dos campos de futebol, tendo, talvez, um perfil mais próximo do torcedor de Copa do Mundo. Segundo Messing, Müller e Schorman (2004), embora a unidade de tempo e espaço conecte os espectadores olímpicos, elas não formam uma massa homogênea. Para estes autores, além de diferenças que eles classificam como estruturais ${ }^{18}$, os espectadores também podem diferenciar-se pelas atitudes em relação aos $\operatorname{Jogos}^{19}$. Podem tanto estar interessados em um círculo pequeno de esportes selecionados quanto serem abertos para o esporte olímpico em geral. É pouco provável que observemos aqui o caráter singular e autônomo que as torcidas organizadas de futebol adquiriram. Deste modo, tornase mais real a possibilidade de constituir uma ordem de interação em contextos que a microssociologia chama de interação não-focalizada (JOSEPH, 2000) ${ }^{20}$.

Um exemplo típico de construção de uma ordem de interação são os animadores de torcida. Sua presença parece estar amplificada, oficializada e colocada em um contexto de um espetáculo de entretenimento bem produzido. Há música antes, após e durante cada momento no qual não haja competição ${ }^{21}$. Em muitas modalidades, dançarinas contratadas exibem pequenas coreografias a cada pedido de tempo ou intervalo. Atores fantasiados como as mascotes brincam com a plateia entre um jogo e outro como se fosse um circo ou um show. Apresentadores conduzem

18. Tanto as sóciodemográficas quanto as determinadas por vinculações com os próprios Jogos (ser atleta, jornalista, dirigente, patrocinador e etc).

19. Orientação para o resultado, orientação para a experiência, orientação para o processo e orientação para a sociabilidade.

20. Entendidas como formas de comunicação interpessoal que resultam da simples copresença.

21. Na Arena Olímpica do Pan-americano de 2007, havia mesmo uma iluminação com holofotes coloridos girantes dando um efeito parecido com o de uma boate ou show. 
pequenos jogos e desafios com o público no intervalo. Tudo parece estar preparado para manter uma excitação constante ${ }^{22}$.

Porém, mais importante do que isto é observar as formas de convocação pública que vêm sendo engendradas para comandar as movimentações e cantos da torcida. Elas podem ser de três formas. Em primeiro lugar, pela alocação de um profissional, geralmente com uma roupa chamativa, no meio da torcida para comandá-la. Em segundo lugar, pelo apresentador que comanda coreografias ${ }^{23} \mathrm{e}$ gritos de incentivo antes do jogo, durante os intervalos ou mesmo entre um ponto e outro em algumas modalidades. Por fim, pelo próprio painel eletrônico que, mais do que um placar tornou-se uma ferramenta de comunicação e entretenimento. Por meio dele, a direção do espetáculo pode pedir que se batam palmas para uma jogada bonita ou que se faça uma hola, induzindo uma forma coletiva e correta de torcer durante a competição. Neste contexto, valoriza-se uma excitação amistosa e jocosa, jamais agressiva. Há uma expectativa mais ou menos construída de exibição de fair play entre o público e de modos de comportamento que os tornam mais espectadores do que torcedores. Com efeito, os comportamentos tendem a satisfazer uma condição estrutural: relacionam disposições sensoriais diversas e uma linguagem corporal feita de movimentos, gestos e atitudes; uma "rendição", tal como no vocabulário de Simmel sobre a reciprocidade.

\section{OS ESPAÇOS OLÍMPICOS CRIAM UMA DIMENSÃO SENSORIAL}

Uma característica importante dos espaços é sua ambientação. Sua configuração atua de maneira complementar às lutas pela definição da destinação do espaço e do estabelecimento de suas fronteiras, configurando-se reciprocamente. Também pode ser dito que funcionam como um "quadro", ou seja, um dispositivo cognitivo e prático de atribuição de sentido que rege a interpretação de uma situação e o engajamento nessa situação. Curiosamente, neste caso, este quadro torna-se também o produto de uma tensão entre um sentido internacional (olímpico) e um sentido local (Chinês, no caso). No caso de Beijing, organizar os Jogos era uma maneira de demonstrar ao mundo sua capacidade de realização, de buscar uma forma visível de celebrar seu status de potência mundial e, ao mesmo tempo, de

22. Em minha experiência, por vezes havia um desencaixe entre esta excitação fabricada e o clima do jogo. Ora porque o jogo não era nada excitante, ora porque o jogo era excitante o suficiente. Um exemplo reside no jogo final do basquete masculino entre EUA e Espanha, quando o elevado desempenho espanhol tornou o resultado quase imprevisível. Naquele evento, as dançarinas e as músicas se tornaram um acontecimento completamente deslocado e sem sentido.

23. Por exemplo: holas, batidas de pé e acenos. 
enfatizar sua identidade e a força de sua cultura e tradições (CLOSE; ASKEW; XIN, 2007). Tudo isto, contraditoriamente, por meio da realização de um evento claramente enraizado na tradição da cultura ocidental24

A cidade olímpica se define sensorialmente por suas bandeiras, cartazes, sinalizações, jardins, cores, propagandas e símbolos específicos visíveis praticamente desde o momento que se deixa o avião. Esses sinais carregam os Anéis Olímpicos, imagens da Tocha Olímpica, grafismos diversos com as cinco cores dos anéis, a logomarca dos Jogos, imagens dos mascotes e dos patrocinadores. Seu contraponto é seu patrimônio cultural, sua urbanização específica, sua população e seus costumes, às vezes alheios à realização dos Jogos.

A ambientação colorida e embandeirada da Beijing criou a expectativa de viver a mesma festa de rua que presenciei no Rio e em Sydney, especialmente. Todavia, não havia por parte do governo local nenhum interesse na formação de aglomerações humanas. Em toda a cidade havia apenas um telão na rua ${ }^{25}$, nenhuma programação cultural externa e uma quantidade extraordinária de guardas de todos os tipos e em todos os lugares ${ }^{26}$. Algo bastante diverso dos telões, espetáculos, performances e da festa de rua que se transformou Sydney ou mesmo da praça das medalhas em Copacabana, no Rio. Curiosamente, a maior "festa" de rua que presenciei foi a cerimônia diária de descerramento da bandeira chinesa na Praça Tienanmen, que por seu caráter marcial atrai muitos turistas. Assim, a festa, esta importante forma de socialização e de reversão das separações prévias, era algo bastante limitado e seu sentido deslocado. Assim, se as cidades olímpicas parecem estar cada vez mais parecidas, parece claro que, no caso chinês, o envolvimento da cidade no evento estava condicionado pelo grau de liberdade desejado e permitido pelo governo.

Uma observação mais atenta levou-me a perceber a existência de um padrão estético mais ou menos constante entre as cidades-sede mais recentes. Num plano mais geral, isto pode ser percebido na maneira de escrever o nome da cidade (de uma forma que sugere o "escrito à mão"), nas cores (com evidente predominância do azul), nos grafismos nos uniformes (sugerindo movimento, seja do ar, seja das águas), além, é claro, no uso inescapável dos símbolos olímpicos. Os uniformes

24. Deve ser reconhecido que uma forma típica de celebração identitária nos Jogos Olímpicos é a cerimônia de abertura. Para fins desse trabalho, contudo, este elemento não será discutido.

25. Colocado de tal modo transversal, que o melhor lugar para assisti-lo era no segundo andar de uma loja Kentucky Fried Chicken.

26. Foi noticiada antes dos Jogos a arregimentação de 400 mil guardas voluntários temporários. Com suas faixas vermelhas escritas em mandarim e inglês, era possível ver de aposentados a varredores de rua atuando também como vigilantes da ordem pública por todo o lado. 
dos voluntários podem ser tomados como um caso típico. Apesar de as últimas três edições dos Jogos terem se realizado em países tão diferentes quanto Austrália, Grécia e China ${ }^{27}$, sempre era possível observar os uniformes de calças bege em estilo cargo e as blusas polo azuis com grafismos que sugerem movimento ${ }^{28}$, nos quais as logomarcas dos Jogos faziam uma aparição maior nas costas do que na frente.

De modo mais específico, isto está presente nas maneiras de sinalizar, organizar e decorar os espaços olímpicos. A mesma semelhança presente nos uniformes tornou-se visível também na ambientação dos espaços, nas cores, nos grafismos e também nos ícones de sinalização amarelos, de formato arredondado ${ }^{29}$, apesar de cada cidade ter e exibir sua logomarca e mascotes próprios. É claro que os gritos da maioria dos torcedores e, por vezes, as apresentações artísticas de elementos da cultura chinesa, não deixam esquecer completamente onde se está.

A semelhança sensorial parece criar um dispositivo de atribuição de sentido que se torna cada vez mais forte por meio da repetição, auxiliando a definir o ambiente olímpico como algo supranacional, com suas formas próprias de ação e de valores. Assim, as marcas identitárias do projeto universalista do Movimento Olímpico não eliminam mas superam, em seu ambiente específico, as possibilidades de singularização daquela edição da competição ${ }^{30}$. Comparativamente, pouca diferença fazia estar em Sydney ou Beijing.

\section{A FLUIDEZ DOS ESPAÇOS OLÍMPICOS}

Um dos atributos do espaço, segundo Simmel, é a condição deles poderem ser trocados ou, quando na condição de uso por grupos sedentários, se tornarem fluidos a ponto de gerarem consequências singulares que afetam os pressupostos dos atributos anteriores. Irei considerar esta questão a partir das duas dimensões espaciais do objeto analisado.

Pareceu-me evidente a pouca fluidez dos espaços olímpicos específicos. Como tentei demonstrar, as instalações olímpicas tinham suas destinações, delimitações, expectativas de atuação e produção sensorial bem definidas e estruturadas. Em oposição, considerar a própria cidade como um espaço olímpico remete a um campo de possibilidades bem mais amplo, uma vez que pressupõe considerar

27. Vale observar que entre estes países, apenas a Grécia usa o azul como cor nacional.

28. Em oposição ao púrpura e verde que dominavam os uniformes em Atlanta 1996.

29. Chamou-me à atenção o quanto eram semelhantes em forma, cores e diagramação as placas de sinalização do Pan do Rio e dos Jogos de Beijing.

30. Segundo minhas observações, isto também pode ser válido quanto se compara com os Jogos Panamericanos do Rio em 2007. 
como a pluralidade da vida social local é afetada pela organização dos Jogos. Que rearrumações dos espaços urbanos são feitas em seu nome? Que classes e grupos são afetados e/ou manipulam os impactos espaciais dos Jogos em seu beneficio próprio? Que imagens e identidades são escolhidas para serem legitimadas internamente e projetadas externamente?

Este foi um desafio praticamente intransponível naquele momento. $O$ fato de ter acumulado alguma informação prévia a partir da imprensa sobre alguns impactos dos Jogos para sua população, e ter obtido indícios de sua verificabilidade, ou mesmo contar com a sorte de ter colegas chineses para obter informações pessoais, não permitiam que eu me considerasse equipado para interpretar a cultura local e como ela interagiu com os Jogos. A começar pela barreira da língua, uma vez que poucos chineses se comunicavam em inglês e eu ainda menos em seu idioma, havia uma impossibilidade de compreender seriamente a cultura local em sua complexidade e como ela foi impactada pelos Jogos. Além disso, por vezes, a própria condição de observador ficava em questão. Quanto mais me afastava dos espaços "olímpicos"e das zonas mais intensamente frequentadas por turistas, mais me transformava de observador em observado. Mesmo no transporte de massa, era bastante perceptível o olhar observador que os moradores dirigiam a mim. Nas condições específicas do contexto e no fato de ser um observador em movimento, tinha poucas condições de "banalizar" minha presença no cenário, embora isto não fosse, de fato, algo fundamental para o tipo de investigação que me propus a realizar.

Como toda cidade olímpica, Beijing passou por uma série de intervenções urbanas quase sempre já previstas e que tomam impulso por meio dos Jogos. Sete grandes linhas de metro assim como a ampliação ou construção de avenidas e anéis viários foram feitas para preparar a cidade. Suas indústrias mais poluidoras foram movidas para outros lugares ${ }^{3 !}$. Fala-se, contudo, em cerca de um milhão e meio de residentes deslocados para a realização destas obras.

A vagueação pela cidade apenas me fez observar como a ornamentação da cidade foi ampliada pela colocação de flores, ainda em seus saquinhos pretos, em torno das árvores, os cartazes incentivando a população a fazer fila nos pontos de ônibus e a renitência do hábito de escarrar em público, apesar da notícia de campanhas contra isto e outras coisas antes de receber os turistas. Pude observar ainda a repetição da vaga nacionalista já vista em Sydney, materializada na multiplicação das aparições da bandeira nacional em diferentes tamanhos e formatos e da cobertura da mídia local quase que exclusiva de seus heróis.

31. Não encontrei comentários sobre o que foi feito de seus funcionários. 
Finalmente, apenas como uma nota, vale comentar o manuseio articulado e cuidadoso de tradição e modernidade nas principais construções olímpicas: o estádio (o ninho do pássaro) e o parque aquático (o cubo d'água). Ambos foram construídos no extremo norte na cidade, em meio a um novo parque arborizado e dotado de um lago destinado a amenizar seu clima. Todavia, suas formas e localização são cheias de um simbolismo que relacionado às ideias de equilíbrio e tradição. Na tradição chinesa, a forma circular remete às idéias de "céu", "paraíso", enquanto a forma quadrada representa a ideia da terra. A forma retangular do Cubo D'água e a forma circular do Ninho do Pássaro, assim como o posicionamento destas construções uma em frente à outra evocavam a complementaridade destas ideias, encontráveis em outras construções típicas da China, como o Templo do Céu, por exemplo. Do mesmo modo, sua localização no prolongamento de um eixo imaginário que passa por uma série importantes construções antigas ao mesmo tempo em que corta a cidade de norte a sul, parece ter sido planejada como uma mensagem da união entre passado e modernidade no seio da tradição e da continuidade daquela civilização.

Estes fatos são indicadores de como, numa dimensão mais alargada, é possível pensar na fluidez e na reconfiguração dos espaços da cidade a partir da experiência de preparar-se e receber os Jogos Olímpicos, e como isto pôde ser feito a partir de um projeto identitário de nação. Mas, penso que em meu empirismo suave pouco posso dizer sobre isto.

\section{CONCLUSÕES}

Os Jogos adquirem atributos próprios que transcendem a identidade da cidade. A preocupação de demarcá-la como uma "cidade olímpica" acaba por, até certo ponto, apagar sua identidade própria. Sua destinação temporária, suas delimitações criadas, as ações e as trocas realizadas nos espaços públicos e sua ambientação, parecem ter dado um sentido universalista mais preciso para o abstrato lema dos Jogos: "Um mundo, um sonho". De qualquer forma, este evento nos permite pensar na necessidade de investigar como diferentes sociedades têm se apropriado do Movimento Olímpico, dos Jogos Olímpicos e de seus valores proclamados como forma de construção de suas próprias representações coletivas.

Neste caso específico, podemos apostar que a tensão entre o local e o universal parece estar contida entre os diferentes espaços da cidade. De um lado, aqueles dedicados aos Jogos, com suas fronteiras, destinações, valores, práticas e identidade específicas. De outro, os espaços da cidade que influenciados ou 
alterados pelos Jogos, mas que não fazem parte objetiva deles. Pode-se perceber que tais arranjos espaciais entre o local e o universal podem variar segundo sua necessidade e seu sentido para a organização dos próprios Jogos. Neste caso, o caráter autoritário do governo chinês influiu na maneira como o universal e o local se encontravam no espaço público tentando manter seu controle sobre este último. Em contas finais, inspirados em Clifford Geertz, poderíamos pensar que os Jogos se fazem em cidades e não nas cidades o que relativiza e contextualiza os sentidos da ideia de legado olímpico.

Tais dados e reflexões indicam ainda a seriedade de se pensar em um projeto identitário de cidade e sociedade embutido em uma candidatura olímpica como a da cidade do Rio de Janeiro quem o controle e como ele é elaborado, discutido e definido.

\section{Beijing 2008: the olympics, the city and the spaces}

ABSTRACT: The aim of this article is to analyze the organization and the relationship of Beijing and the 2008 Olympics' spaces. We adopted Gidden's concept of 'operational stage', microsociological principles of Goffman and the sociology of spaces categories of Simmel. One could observe the exclusiveness of Olympic spaces, its borders and delimitations. The establish of an expectation of performance and the creation of a sensorial dimension. On the other hand, we faced limits to discuss the fluidity of spaces. As a conclusion, the Games acquire spatial attributes that transcend city's identity and their interaction character seems to be related to the political project of the host country.

KEYWORDS: Olympic Games; spaces; Beijing; city.

\section{Beijing 2008: los juegos olímpicos, la ciudad y los espacios}

RESUMEN: Este artículo tiene como objetivo analizar la organización y la relación de los espacios de Beijing y de los Juegos Olímpicos 2008. Se adoptó como referencia el concepto de 'escenario de operación' de Giddens, los principios de la micro-sociología de Goffman y la sociología del espacio de Simmel. He visto cómo los espacios 'olímpicos' se convierten en exclusivos. Sus fronteras divididas y definidas. Se fijan para una cierta expectativa de rendimiento y para crear una dimensión sensorial de identidad y temporalidad propias. Por otra parte, nos encontramos con los límites para considerar la fluidez de los espacios. En conclusión, los Juegos obtienen atributos espaciales que trascienden la identidad de la ciudad y el carácter de la interacción parece estar relacionada con el proyecto político del país de acogida.

PALABRAS CLAVES: Juegos olímpicos; espacios; Bejing; ciudad. 


\section{REFERÊNCIAS}

ARCHETTI, E. P. The Spectacle of Heroic Masculinity: Vegard Ulvang and Alberto Tomba in the Olympic Winter Games of Albertville. In: KLAUSEN, A. M. (Ed.) Olympic Games as Performance and Public Event. New York: Bergham Books, 1995. p. 195-208.

BEIJING Organizing Committee of the Olympic Games. Ticket - Beach Volley-Ball competition. Beijing, 2008.

BROWNELL, S. Western Centrism in Olympic Studies and Its Consequences in the 2008 Beijing Olympics. In: BARNEY, R. et al. (Orgs.) Pathways: critiques and discourses in olympic research. London, CA: International Centre for Olympic Studies, 2008. p. 20-30.

CLOSE, P.; ASKEW, D.; XIN, X. The Beijing Olympiad. The political economy of a sporting mega-event. New York: Routledge, 2007.

DaCOSTA, L. P. Olympic Studies: Current Intellectual Crossroads. Rio de Janeiro: Ed. Gama Filho, 2002.

DaMATTA, R. Em torno da dialética entre igualdade e hierarquia: notas sobre as imagens e representações dos Jogos Olímpicos e do futebol no Brasil. Antropolítica, n. 14, p. 17-39, I. sem. 2003.

INTERNATIONAL OLYMPIC COMMITTEE. Olympic Charter 2007. Disponível em: < http:// multimedia.olympic.org/pdf/en_report_122.pdf>. Acesso em: 13 mar. 2008.

JACCOUD, M.; MAYER, R. A observação direta e a pesquisa qualitativa. In: POUPART, J. et al. A Pesquisa qualitativa. Enfoques epistemológicos e metodológicos. Petrópolis, RJ: Vozes, 2008.

JOSEPH, I. Erving Goffman e a Microssociologia. Rio de Janeiro: Ed. FGV, 2000.

JULLIEN, F. A arte do desvio. In: MORIN, E. et al. A Sociedade em Busca de Valores. Lisboa: Instituto Piaget, 1996. p. I63-175.

KLAUSEN, A. M. Introduction. In: (Ed.) Olympic Games as Performance and Public Event. New York: Bergham Books, 1995. p. I-8.

LOLAND, S. Coubertin's Ideology of Olympism from the perspective of the History of Ideas. Olympika: The International Journal of Olympic Studies, v. IV, 1995, pp. 49-78.

MacALOON, J. Encoutering Our Others: Social Science and Olympic Sport. In: KANG, S.P.; MacALOON, J. DaMATTA, R. (Orgs.) The Olympics and Cultural Exchange. Seul: The Institute for Ethnological Studies / Hanyiang University, 1987. p. I5-4I.

MESSING, M.; MÜLLER, N.; SCHORMAN, K. Local Visitors and Tourists at the Modern Pentathlon in Sydney 2000 - a Contribution on the Internal Differentiation of an Olympic 
Spectator. In: MESSING, M.; MÜLLER, N.; PREUSS, H. (Hg.) Olympischer Dreiklang. Werte - Geschichte - Zeitgeist. Kassel: Agon Sportverlag, 2004. p. 365-406.

SAID, W. E. Orientalismo. O oriente como invenção do ocidente. São Paulo: Cia. das Letras, 2007.

SCHRADER, A. Métodos de pesquisa empírica e indicadores sociais. Porto Alegre: Ed. Universidade/UFRGS, 2002.

SIMMEL, G. Sociologia. São Paulo: Ática, 1983.

TOLEDO, L. H. Lógicas do Futebol. São Paulo: HUCITEC, 2002.

Recebido: 07 set. 2009 Aprovado: 05 abr. 2011

Endereço para correspondência Otávio Tavares CEFD/UFES Av. Fernando Ferrari, 5 |4 - Goiabeiras Vitória-ES CEP 29075-910 